Article

\title{
Changed Temporal Structure of Neuromuscular Control, Rather Than Changed Intersegment Coordination, Explains Altered Stabilographic Regularity after a Moderate Perturbation of the Postural Control System
}

\author{
Felix Wachholz *, Tove Kockum, Thomas Haid and Peter Federolf \\ Department of Sport Science, University of Innsbruck, 6020 Innsbruck, Austria; \\ tove.kockum@student.uibk.ac.at (T.K.); thomas.haid@uibk.ac.at (T.H.); peter.federolf@uibk.ac.at (P.F.) \\ * Correspondence: felix.wachholz@student.uibk.ac.at
}

Received: 20 May 2019; Accepted: 19 June 2019; Published: 21 June 2019

\begin{abstract}
Sample entropy (SaEn) applied on center-of-pressure (COP) data provides a measure for the regularity of human postural control. Two mechanisms could contribute to altered COP regularity: first, an altered temporal structure (temporal regularity) of postural movements (H1); or second, altered coordination between segment movements (coordinative complexity; $\mathrm{H} 2$ ). The current study used rapid, voluntary head-shaking to perturb the postural control system, thus producing changes in COP regularity, to then assess the two hypotheses. Sixteen healthy participants (age $26.5 \pm 3.5$; seven females), whose postural movements were tracked via 39 reflective markers, performed trials in which they first stood quietly on a force plate for $30 \mathrm{~s}$, then shook their head for $10 \mathrm{~s}$, finally stood quietly for another $90 \mathrm{~s}$. A principal component analysis (PCA) performed on the kinematic data extracted the main postural movement components. Temporal regularity was determined by calculating SaEn on the time series of these movement components. Coordinative complexity was determined by assessing the relative explained variance of the first five components. $\mathrm{H} 1$ was supported, but $\mathrm{H} 2$ was not. These results suggest that moderate perturbations of the postural control system produce altered temporal structures of the main postural movement components, but do not necessarily change the coordinative structure of intersegment movements.
\end{abstract}

Keywords: temporal regularity; coordinative complexity; motor control; center of pressure COP; principal component analysis PCA; balance; perturbation; neuroscience

\section{Introduction}

Human postural control is the ability to keep the human body in an upright position and stay balanced [1]. However, numerous neurological impairments, such as concussion [2], autism [3], stroke [4], cerebral infarction [5], Parkinson's [6], a hearing deficit [7], Ehlers-Danlos syndrome [8], idiopathic scoliosis [9], cerebral palsy [10], or down syndrome [11] affect and often compromise postural control. Moreover, physiological states like fatigue, e.g., in the hip and ankle muscle [12] or the general lower extremity [13], were also shown to have an effect on postural control. The age factor has an impact on the postural control system [14], as well as alterations that affect the system by disturbing the "normal state", like dual-tasking situations [15] or when less sensory input is received after closing the eyes [16]. Several studies report effects on postural control after rapid head movements-for example, in patients with compromised vestibular function [17], in the elderly [18], or in sports like soccer (after heading the ball) [19]. 
To evaluate differences in postural control, a common method is to analyze center-of-pressure (COP) data. COP data can be analyzed using different approaches, such as stabilogram diffusion [20] or using COP displacement [21]. Another method that has gained attention and validation over recent years is using sample entropy ( $\mathrm{SaEn}$ ) of COP data [22]. SaEn can be described as a measure of regularity adapted to strings of data in a time series $[16,23]$. Research suggests that compromised postural control systems tend to produce more regular (low-SaEn-value) movements compared to healthy postural control systems, which typically show less regularity (high SaEn-value). This was shown, for example, in patients suffering from concussion [2,24,25], Ehlers-Danlos syndrome [8], idiopathic scoliosis [9], or multiple sclerosis [26]. Moreover, evaluating COP entropy to assess postural control has, in several situations, proved to be more sensitive than traditional COP measures [2,27].

$\mathrm{COP}$ entropy is often interpreted as a measure of the regularity of the COP time series [28-30], and thus of the postural changes that produced the COP movement. Even during a quiet stance, several types of postural changes have been discussed, e.g., ankle, hip, [31,32] and higher-order movement strategies [33]. COP regularity could therefore be a measure for the regularity of the temporal structure of the underlying movement strategies (hypothesis 1), thus characterizing the temporal structure of the individual movement strategies. However, we could also speculate that a more complex interplay of the segment movements increases the irregularity of the COP trajectory (hypothesis 2). In the latter case, COP regularity would be a measure for the complexity of the coordinative structure of the inter-segment movements. A measure for coordinative complexity could be the dimensionality [34] of the postural movements, assessable through a principal component analysis (PCA) on kinematic movement data recorded during a balancing exercise [33,35-37]. In a recent study by our group [38], we investigated the two proposed hypotheses for the origins for COP regularity with a cross-sectional study design. We measured COP motion, as well as the kinematic movements of all body segments through a marker-based motion tracking system, and performed a principal component analysis on the kinematic marker data to obtain a representation of the postural movement strategies; we could thus assess the temporal regularity by calculating the entropy of the dominant movement components, as well as the dimensionality of the postural movements by calculating the cumulative variance, $r$ CUM $M_{x}$, which expresses (in percent) how much the first $x$ movement components contribute to the overall variance of a person's postural variance [38] (high $r C U M_{x}$ indicates lower dimensionality, i.e., a less complex movement structure, while a lower $r C U M_{x}$ suggests that more movement strategies contributed to the overall movement, i.e., a more complex motion). We found that between subjects, COP regularity correlated with both the temporal regularity of the underlying movement components, as well as with the dimensionality of the postural movements [38]. The purpose of the current study was to investigate the two potential sources of altered COP regularity with an intervention study design.

In summary, the current study was conducted to better understand what COP entropy, or more specifically a change in COP entropy, signifies for the actual postural movements that produced the analyzed COP trajectory. Thereto, the goal was to moderately perturb the postural control system of the volunteers through rapid, voluntary head movements, in order to produce changes in COP entropy. We could then assess the two hypotheses by determining whether changes in COP regularity were accompanied by changes in the regularity of the temporal structure in individual movement components (hypothesis 1), or by changes in the dimensionality of the overall postural movement (hypothesis 2). Two types of head movements, nodding and tilting (ear-to-sholder), were used to disturb the postural control system. Furthermore, since differences in postural control are often found between eyes open and eyes closed conditions, we also evaluated if differences can be found between performing the tests with open or closed eyes. 


\section{Materials and Methods}

\subsection{Ethics}

Before performing the measurements, all participants were informed about the procedures and about possible risks involved. All participants gave written informed consent and were informed that they could withdraw from the experiment at any time without reason. The study was approved by the board for Ethical Questions in Science of the University of Innsbruck (52/2017) and all procedures were performed in accordance with the Declaration of Helsinki.

\subsection{Participants}

A convenience sample of 16 healthy and physically active volunteers was analyzed in the current study (see Table 1). Exclusion criteria were neurological disorders or injuries sustained within the last six months, as well as pathological joint, tendon, or muscle problems.

Table 1. Characteristics of the participants (mean $\pm \mathrm{SD}$ ).

\begin{tabular}{cccc}
\hline Participants & Age & Body Weight $\mathbf{( k g )}$ & Body Height (cm) \\
\hline All $[n=16]$ & $26.5 \pm 3.5$ & $69.3 \pm 14.6$ & $176.6 \pm 11.0$ \\
Female $[n=7]$ & $27.1 \pm 3.3$ & $54.6 \pm 5.4$ & $165.3 \pm 4.9$ \\
Male $[n=9]$ & $26.0 \pm 3.6$ & $80.8 \pm 7.3$ & $185.2 \pm 4.8$ \\
\hline
\end{tabular}

\subsection{Measurement Procedures}

The participants performed a 5 min warm-up before the actual measurement, which included shoulder movements and flexing neck muscles. For the actual measurements, participants were instructed to stand as steady as possible in a hip-wide stance, with their hands on the hips and their gaze focused on a sign placed $5.5 \mathrm{~m}$ in front them, at a height of $1.75 \mathrm{~m}$. Each measurement trial lasted $130 \mathrm{~s}$ and consisted of three parts. For the first $30 \mathrm{~s}$, the participants were instructed to stand as still as possible. Then, in response to a signal from the experimenter, the participants were to shake their head for $10 \mathrm{~s}$. Completion of this part was indicated to the participants through another signal from the experimenter. The number of performed headshakes was quantified by the movement of the markers attached to the head and are displayed in Table 2. After the headshaking, participants were to continue with a quiet stance for another $90 \mathrm{~s}$. The headshaking was completed at volunteers own pace and at self-chosen range of motion. Participants were instructed to, on the one hand, shake as fast as possible and, on the other hand, to do it in a way that felt safe and did not compromise standing stability or control of motion. Some volunteers reported the sensation of a light dizziness after the head shaking part in some of their trials; however, this did not occur systematically and was not further analyzed in the current study. In total, four trials were completed per participant in a randomized order. Two different methods of head shaking where conducted: in the anterior-posterior direction, comparable to a "nodding" motion; and medio-laterally, which can be described as tilting the head sideways (ear-to-shoulder). Both trials were executed once with eyes open and once with eyes closed. Hence, every participant did one trial per head shake, resulting in four trials per participant. Between the trials, participants had at least $60 \mathrm{~s}$ of rest in which they could walk around in the room.

Table 2. Number of headshakes (full cycles) per second (mean \pm SD).

\begin{tabular}{ccccc}
\hline \multirow{2}{*}{ Trial } & Nodding Head & Nodding Head & Tilting Head & Tilting Head \\
\cline { 2 - 5 } & Eyes Open & Eyes Closed & Eyes Open & Eyes Closed \\
\hline $\begin{array}{c}\text { headshakes per second, } \\
\text { averaged over all participants }\end{array}$ & $2.0 \pm 0.6$ & $2.1 \pm 0.6$ & $1.8 \pm 0.4$ & $1.7 \pm 0.4$ \\
\hline
\end{tabular}




\subsection{Instrumentation}

Center-of-pressure motion was recorded at $3000 \mathrm{~Hz}$ using a ground-embedded AMTI force plate (AMTI, Watertown, NY, USA). Kinematic data quantifying postural movements of the body were collected at $150 \mathrm{~Hz}$ using an eight-camera Vicon motion tracking system (Vicon Motion Systems Ltd., Oxford, UK). In total, 39 retro-reflective markers were attached to anatomical landmarks on the skin or on tight clothing, using double-sided tape. Markers on the wrists and head were attached using modified sweatbands. The marker model was based on the full-body Plug-In Gait marker model of Vicon. Force plate and kinematic data were synchronously collected using the Vicon software (Vicon Nexus, Version 2.2.3; Vicon Motion Systems Ltd., Oxford, UK).

\subsection{Data Processing}

Kinematic and COP data were further analyzed using MatLab ${ }^{\text {TM }}$ R2015b (The Mathworks Inc., Natick, MA, USA). From each trial, three $15 \mathrm{~s}$ phases were extracted (Figure 1). Phase 1 was taken from the period before the headshake, from second 5 to second 20 . The first five seconds were omitted to evade movements related to starting the measurement. The second $15 \mathrm{~s}$ phase started as soon as the headshake had stopped, which was separately established for each trial, by determining when the movement of the markers placed on the head no longer exceeded quiet-standing movements. Phase 3 was selected right after the end of phase 2, since in this phase postural control had returned to normal (Figure 1), and since we wanted to avoid effects of fatigue or impatience, which were sometimes observed later in a trial.
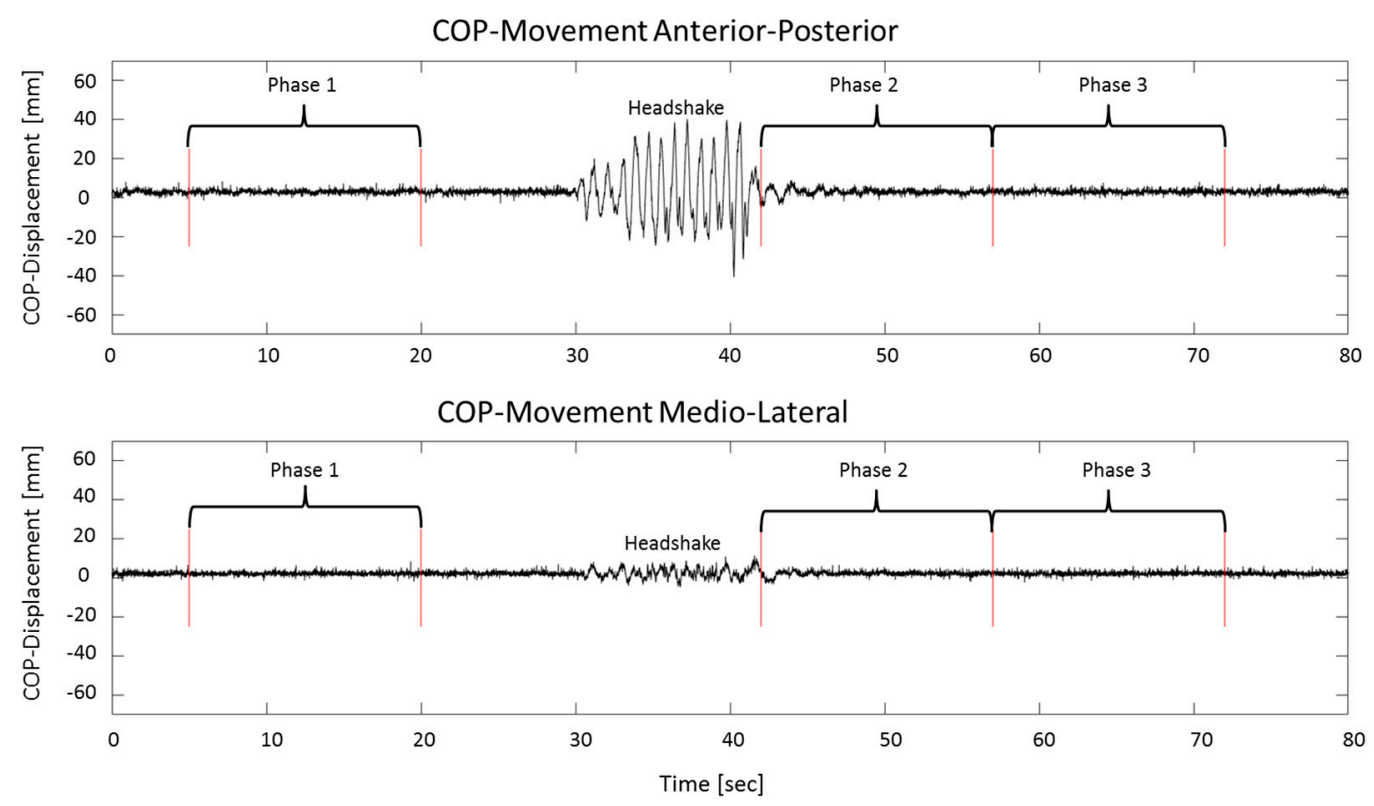

Figure 1. Center-of-pressure (COP) data of one sample trial of an anterior-posterior head shake with open eyes. The graph on top shows the anterior-posterior COP movement, the bottom graph shows the medio-lateral COP movement. The three analyzed phases are indicated. The last $50 \mathrm{~s}$ were omitted to better visualize the relevant phases of the trial.

\subsection{Processing of Center-of-Pressure Data}

The COP data was down-sampled to $150 \mathrm{~Hz}$ and de-trended using a moving average calculated from the surrounding 300 neighboring points of each data point. The first and last 150 data points were padded with the first and last de-trended data point, respectively. The anterior-posterior $\operatorname{COP}_{A P}(t)$ and the medio-lateral component $\mathrm{COP}_{M L}(t)$ of the $\mathrm{COP}$ were analyzed separately. 


\subsection{Processing of Kinematic Data: Calculation of Principal Movements (PMs)}

The kinematic data of each phase was gap-filled [39,40], centered by subtracting the subject mean [33], normalized to the mean Euclidean distance [36,41], and weighted according to the relative weight represented by each marker [42]. The data sets of the three phases from all subjects were concatenated to create a $432,000 \times 117$ input matrix for the PCA (lines: 16 subjects, four trials, with three phases of $15 \mathrm{~s}$ recorded at $150 \mathrm{~Hz}$; columns: 39 three-dimensional (3D) marker coordinates). Each row of the matrix contains the available information about the posture of a participant at a certain time point, and was interpreted as an 117-dimension posture vector [36,43-46]. After normalizing and concatenating the data from all participants and all trials, one PCA could be calculated for the whole dataset, which has the advantage that the resultant movement components can be directly compared between trials and participants. The PCA was calculated as eigenvector decomposition of the covariance matrix of the data. The PCA created a new basis (eigenvectors) in the vector space of posture vectors. PCA applied to kinematic movement data outputs eigenvectors $P C_{k}$ (where $k$ indicates the order of the eigenvectors), which each describe one linear pattern of correlated marker motion. The PCA also outputs scores $P P_{k}(t)$ and eigenvalues $E V_{k}$. The scores are a representation of the posture vectors in the new $P C_{k}$-basis, and are obtained by projecting the original data on the new basis, i.e., by a basis transformation. We call the scores also "principal positions" $P P_{k}(t)$, since they represent positions in posture space $[36-38,40]$. The eigenvectors $P C_{k}$ and their associated principal positions $P P_{k}(t)$ together define one (the $k$-th) component of the whole postural movements. We call these movement components "principal movements" $\left(P M_{k}\right)$. The $E V k$ are an indicator of the contribution of each $P M_{k}$ to the overall postural variance created by all participants [38,43-46]. To obtain an analogue, subject-specific variable, we determine from $P P_{k}(t)$ the relative variance $r V A R_{k}$ that each $P M_{k}$ contributes to the participant's entire postural variance [33]. Further, the values of the $r V A R_{k}$ were cumulated to calculate the cumulative relative variance $r C U M$ representing the dimensionality of the movement [47], thus providing a measure for what we described as coordinative complexity.

\subsection{Sample Entropy Calculation}

The regularity of $\operatorname{COP}_{A P}(t), \mathrm{COP}_{M L}(t)$ and of the first $10(k=1 \ldots 10) P P_{k}(t)$ time series was determined by calculating the sample entropy (SaEn). The SaEn-algorithm was computed with the parameters' embedding dimension $m=2$ and tolerance $r=0.2 \cdot \mathrm{STD}$, where STD is the standard deviation of the time series [48]; a time delay $\tau$ was chosen that corresponds with physiological time-scales-specifically, $\tau$ was set to $\tau=15$, corresponding to $100 \mathrm{~ms}$ [49]. For the calculation of the regularity of the $P P_{k}$ time series, the same parameters were chosen. The choice of these parameters over a wide range of values did not affect the ranking of the SaEn values, nor of the conclusions that could be drawn from the subsequent statistical evaluation (see Supplementary Material S1), which agreed with earlier observations [38].

\subsection{Statistics}

Dependent variables were $\operatorname{SaEn}\left(C O P_{A P}\right), \operatorname{SaEn}\left(C O P_{M L}\right), \operatorname{SaEn}\left(P P_{k}\right), r V A R_{k}$ and $r C U M_{k}$. Shapiro-Wilk tests were used to test for normal distribution, and the Greenhouse-Geisser correction was performed if the sphericity condition was not met. A one-way, repeated-measure analysis of variance (rANOVA) was used to test for differences between phases (repeated, 3 levels). In the case of significant main effects of phases, a Sidak-corrected post-hoc test was performed to determine where differences originated. If the data was not normally distributed, separate Friedmann tests were performed-in this case, post-hoc tests were calculated using the Dunn-Bonferroni correction. All statistical testing was conducted using SPSS (IBM SPSS Statistics, Version 23); the alpha level was set to $\alpha=0.05$, and partial eta squared $\eta^{2}$ was used to quantify the effect size. 


\section{Results}

\subsection{Center of Pressure Sample Entropy}

Most differences between phases were found in the entropy of the anterior-posterior COP component (Figure 2). Sideways (tilting) head shaking produced significant phase effects with eyes open: $F(1.432,21.474)=6.244, p=0.013, \eta^{2}=0.294$ (post-hoc: phase 2 SaEn was significantly $(p=0.34)$ lower than phase $3 \mathrm{SaEn}$ ); and with eyes closed: $F(1.478,22.163)=10.653, p=0.001, \eta^{2}=0.415$ (post-hoc: phase 1 higher than phase $2(p=0.006)$, and phase 2 lower than phase $3(p=0.025)$. However, nodding the head did not reveal significant differences in $\operatorname{SaEn}\left(C O P_{A P}\right)$, neither with eyes open $(F(1.250,18.754)$ $\left.=3.325, p=0.077, \eta^{2}=0.181\right)$ nor with eyes closed $\left(\chi^{2}(2)=4.500, p=0.105\right)$.

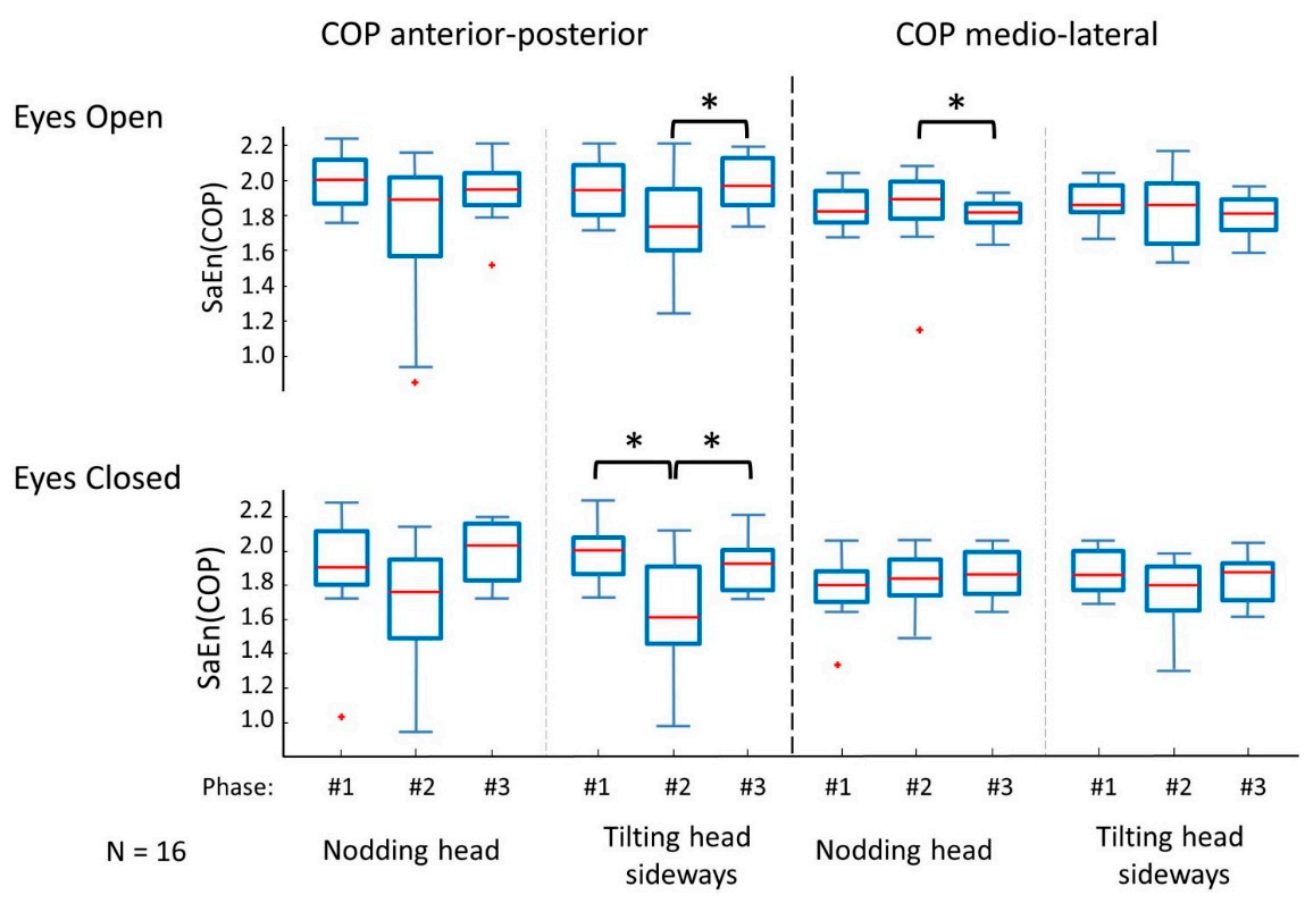

Figure 2. Entropy of the COP time series during $15 \mathrm{~s}$ of quiet standing measured before phase 1, immediately after phase 2 , and later after phase 3 , the $10 \mathrm{~s}$ head shaking exercise. Significant differences between phases are indicated with an asterisk $\left(^{*}\right)$.

In the medio-lateral direction of the COP (Figure 2), significant differences were only found during nodding the head with eyes open $\chi^{2}(2)=10.500, p=0.005$ (post-hoc indicated phase 2 SaEn was different from phase 3: $p=0.004)$. Neither nodding the head with eyes closed $\left(\chi^{2}(2)=2.625, p=0.269\right)$, nor sideways tilting with eyes open $\left(F(1.482,22.229)=2.526, p=0.115, \eta^{2}=0.144\right)$, nor sideways tilting with eyes closed $\left(\chi^{2}(2)=0.875, p=0.646\right)$ caused a significant phase effect in the $\operatorname{SaEn}\left(C O P_{M L}\right)$.

\subsection{Effects of Head Shaking on the Entropy of the Kinematic Movement Components}

The first five PMs described $94.16 \%$ of the total movement variance in the trials. The video sequence attached as Supplementary Material S2 to this paper visualizes these movement components, and Table 3 lists their eigenvalues and gives a qualitative interpretation for what aspect of the total postural movement each PM component quantified. An overview of the effect of head shaking (phase effect) on the entropy of these movement components (in the $P P_{k}$-time series) is given in Table 4 . In summary, in eyes-closed trials, tilting the head produced a significant change in the entropy of all of the first five movement components. In the eyes-open trials, tilting produced a significant change in the entropy of the second, third, fourth, and fifth movement components, but not in the first. Whereas the anterior-posterior head shaking produced significant changes in the four movement components 
$\left(\mathrm{PM}_{1}, \mathrm{PM}_{2}, \mathrm{PM}_{3}\right.$, and $\left.\mathrm{PM}_{4}\right)$ during the eyes-open trial, but did not produce significant changes in any of the movement components during the eyes-closed trials (Table 4).

Table 3. Qualitative description of the first five movement components (PMs) and their eigenvalues, representing each one's contribution to the overall movement.

\begin{tabular}{ccc}
\hline $\mathbf{P M}_{\mathbf{k}}$ & Qualitative Description of $\mathbf{P M}_{\mathbf{k}}$ & $\begin{array}{c}\text { Eigenvalues }_{\mathbf{k}} \\
\text { Share to Whole Motion (\%) }\end{array}$ \\
\hline $\mathrm{PM}_{1}$ & Ankle sway anterior-posterior & 70.67 \\
$\mathrm{PM}_{2}$ & Ankle sway medio-lateral & 12.19 \\
$\mathrm{PM}_{3}$ & Hip strategy (Hip flexion/extension) anterior-posterior & 5.72 \\
$\mathrm{PM}_{4}$ & Lifting shoulders / Breathing & 3.87 \\
$\mathrm{PM}_{5}$ & Upper body rotation & 1.71 \\
\hline
\end{tabular}

Table 4. Statistical results for the effects of head shaking (phase effect) on the entropy of the $P P_{k}$ time series for the four testing conditions based on repeated-measure analysis of variance (rANOVA) (black letters) or Friedmann tests (grey letters). For rANOVA results, partial eta-square $\left(\eta^{2}\right)$ values are reported as a measure of the effect size. Asterisks $\left(^{*}\right)$ indicate significance, and two asterisks $\left(^{* *}\right)$ indicate highly significant head-shaking effects on the entropy of the movement component.

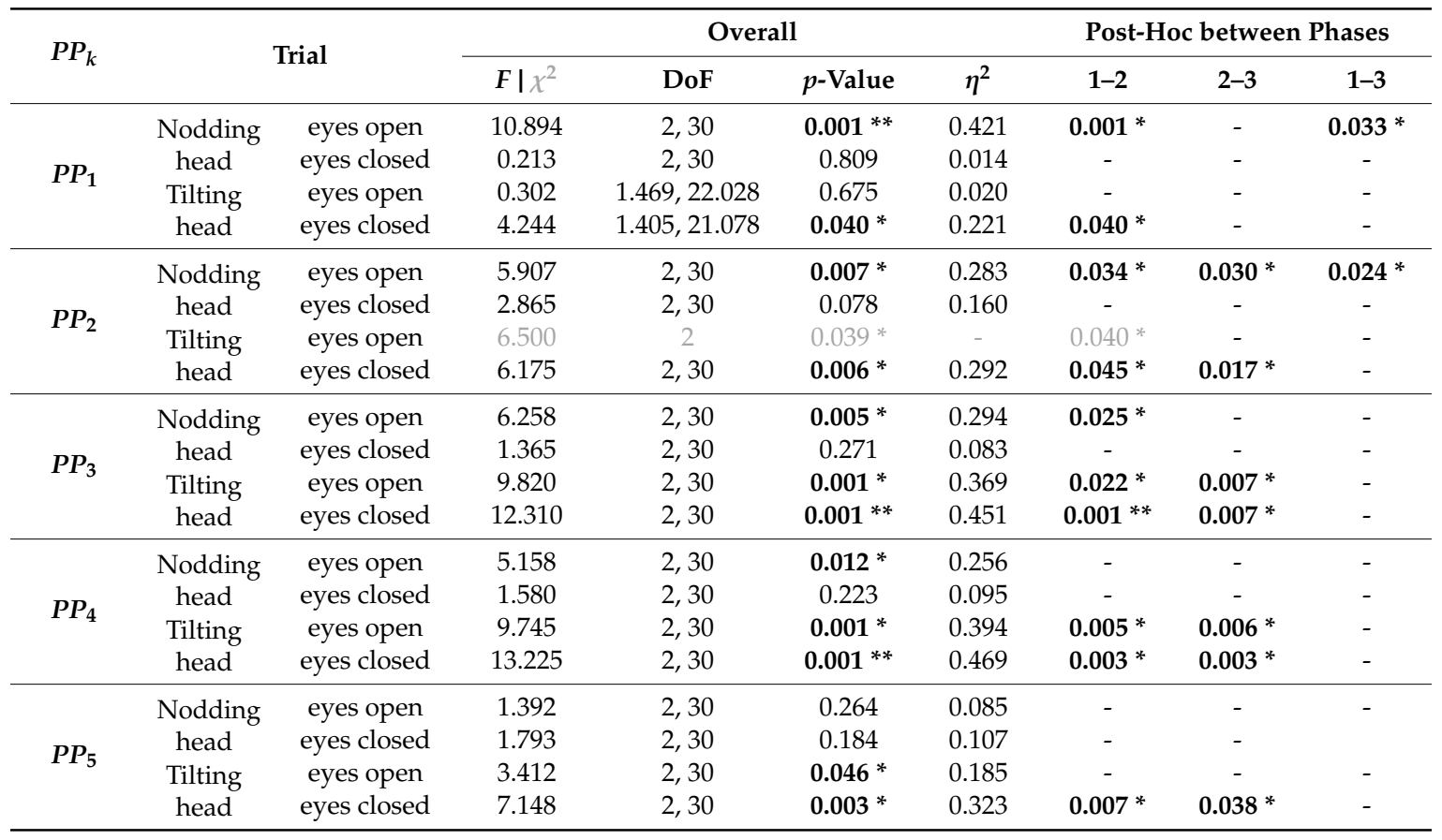

\subsection{Effects of Head Shaking on the Coordinative Complexity of the Postural Movements}

An overview of the effects of head shaking on the relative contribution of each movement component to the overall movement $\left(r V A R_{k}\right)$ and on the cumulated relative variances $(r C U M)$ are given in Tables 5 and 6, respectively. For each variable, only one significant result was observed in all testing situations, as well as in all of the first five movement components. This corresponds to what is expected as a coincidental result ( 1 in 20). The results therefore do not allow adopting the hypothesis that head-shaking had an effect on the coordinative structure or dimensionality of the postural movements. 
Table 5. Statistical results for the effects of head shaking (phase effect) on the relative variance $r V A R$ of $P P_{k}$ for the four testing conditions based on rANOVA. For rANOVA results, partial eta-square $\left(\eta^{2}\right)$ are reported as a measure of the effect size, and $1-\beta$ for the observed power. Asterisks $\left({ }^{*}\right)$ indicate significant head-shaking effects on the relative variance of the movement component.

\begin{tabular}{|c|c|c|c|c|c|c|c|}
\hline \multirow{2}{*}{$P P_{k}$} & \multirow{2}{*}{\multicolumn{2}{|c|}{ Trial }} & \multicolumn{5}{|c|}{ Overall $r V A R_{k}$} \\
\hline & & & $F$ & DoF & $p$-Value & $\eta^{2}$ & $1-\beta$ \\
\hline \multirow{4}{*}{$P P_{1}$} & \multirow{2}{*}{ Nodding head } & eyes open & 1.320 & 2,30 & 0.282 & 0.081 & 0.263 \\
\hline & & eyes closed & 1.719 & 2,30 & 0.196 & 0.103 & 0.332 \\
\hline & \multirow{2}{*}{ Tilting head } & eyes open & 0.625 & 2,30 & 0.542 & 0.040 & 0.145 \\
\hline & & eyes closed & 0.274 & 2,30 & 0.763 & 0.018 & 0.089 \\
\hline \multirow{4}{*}{$P P_{2}$} & \multirow{2}{*}{ Nodding head } & eyes open & 1.228 & $1.480,22.201$ & 0.300 & 0.076 & 0.213 \\
\hline & & eyes closed & 6.387 & 2,30 & $0.005 *$ & 0.299 & 0.870 \\
\hline & \multirow{2}{*}{ Tilting head } & eyes open & 2.023 & 2,30 & 0.150 & 0.119 & 0.384 \\
\hline & & eyes closed & 0.473 & 2,30 & 0.628 & 0.031 & 0.120 \\
\hline \multirow{4}{*}{$P P_{3}$} & \multirow{2}{*}{ Nodding head } & eyes open & 2.691 & 2,30 & 0.084 & 0.152 & 0.492 \\
\hline & & eyes closed & 0.977 & 2,30 & 0.388 & 0.061 & 0.204 \\
\hline & \multirow{2}{*}{ Tilting head } & eyes open & 1.418 & 2,30 & 0.258 & 0.086 & 0.280 \\
\hline & & eyes closed & 0.093 & 2,30 & 0.912 & 0.006 & 0.063 \\
\hline \multirow{4}{*}{$P P_{4}$} & \multirow{2}{*}{ Nodding head } & eyes open & 0.601 & 2,30 & 0.555 & 0.039 & 0.141 \\
\hline & & eyes closed & 0.294 & 2,30 & 0.748 & 0.019 & 0.092 \\
\hline & \multirow{2}{*}{ Tilting head } & eyes open & 0.175 & 2,30 & 0.840 & 0.012 & 0.075 \\
\hline & & eyes closed & 0.737 & 2,30 & 0.487 & 0.047 & 0.163 \\
\hline \multirow{4}{*}{$P P_{5}$} & \multirow{2}{*}{ Nodding head } & eyes open & 0.726 & $1.415,21.218$ & 0.450 & 0.046 & 0.141 \\
\hline & & eyes closed & 0.574 & 2,30 & 0.569 & 0.037 & 0.136 \\
\hline & \multirow{2}{*}{ Tilting head } & eyes open & 0.583 & 2,30 & 0.564 & 0.037 & 0.138 \\
\hline & & eyes closed & 0.476 & 2,30 & 0.626 & 0.031 & 0.121 \\
\hline
\end{tabular}

Table 6. Statistical results for the effects of head shaking (phase effect) on the relative cumulative variance $r C U M$ of $P P_{k}$ for the four testing conditions based on rANOVA (black letters) or Friedmann tests (grey letters). For rANOVA results partial eta-square $\left(\eta^{2}\right)$ are reported as a as measure of the effect size, and $1-\beta$ for the observed power. Asterisks $\left(^{*}\right)$ indicate significant head-shaking effects on the relative variance of the movement component.

\begin{tabular}{|c|c|c|c|c|c|c|c|}
\hline \multirow{2}{*}{$P P_{k}$} & \multirow{2}{*}{\multicolumn{2}{|c|}{ Trial }} & \multicolumn{5}{|c|}{ Overall rCUM } \\
\hline & & & $F \mid \chi^{2}$ & DoF & $p$-Value & $\eta^{2}$ & $1-\beta$ \\
\hline \multirow{4}{*}{$P P_{1}$} & \multirow{2}{*}{ Nodding head } & eyes open & 1.320 & 2,30 & 0.282 & 0.081 & 0.263 \\
\hline & & eyes closed & 1.719 & 2,30 & 0.196 & 0.103 & 0.332 \\
\hline & \multirow{2}{*}{ Tilting head } & eyes open & 0.625 & 2,30 & 0.542 & 0.040 & 0.145 \\
\hline & & eyes closed & 0.274 & 2,30 & 0.763 & 0.018 & 0.089 \\
\hline \multirow{4}{*}{$P P_{2}$} & \multirow{2}{*}{ Nodding head } & eyes open & 3.917 & 2,30 & $0.031 *$ & 0.207 & 0.661 \\
\hline & & eyes closed & 0.032 & 2,30 & 0.968 & 0.002 & 0.054 \\
\hline & \multirow{2}{*}{ Tilting head } & eyes open & 1.004 & 2,30 & 0.378 & 0.063 & 0.208 \\
\hline & & eyes closed & 0.206 & 2,30 & 0.815 & 0.014 & 0.079 \\
\hline \multirow{4}{*}{$P P_{3}$} & \multirow{2}{*}{ Nodding head } & eyes open & 2.816 & 2,30 & 0.076 & 0.158 & 0.551 \\
\hline & & eyes closed & 0.524 & 2,30 & 0.597 & 0.034 & 0.128 \\
\hline & \multirow{2}{*}{ Tilting head } & eyes open & 0.765 & 2,30 & 0.474 & 0.049 & 0.168 \\
\hline & & eyes closed & 0.178 & 2,30 & 0.838 & 0.012 & 0.075 \\
\hline \multirow{4}{*}{$P_{4}$} & \multirow{2}{*}{ Nodding head } & eyes open & 2.822 & 2,30 & 0.075 & 0.158 & 0.512 \\
\hline & & eyes closed & 0.500 & 2 & 0.779 & - & - \\
\hline & \multirow{2}{*}{ Tilting head } & eyes open & 0.966 & 2,30 & 0.392 & 0.060 & 0.202 \\
\hline & & eyes closed & 0.141 & 2,30 & 0.869 & 0.009 & 0.070 \\
\hline \multirow{4}{*}{$P P_{5}$} & \multirow{2}{*}{ Nodding head } & eyes open & 2.823 & 2,30 & 0.075 & 0.158 & 0.513 \\
\hline & & eyes closed & 1.625 & 2 & 0.444 & - & - \\
\hline & \multirow{2}{*}{ Tilting head } & eyes open & 0.876 & 2,30 & 0.427 & 0.055 & 0.187 \\
\hline & & eyes closed & 2.625 & 2 & 0.269 & - & - \\
\hline
\end{tabular}




\section{Discussion}

\subsection{Main Results}

The purpose of the current study was to determine the origin of changes in COP regularity (quantified through SaEn of the COP time series) in response to moderate perturbations of the human postural control system. We hypothesized that changes in the regularity of movement components could produce changes in COP regularity (hypothesis 1), or that changes in coordinative complexity (i.e., changes in the structure and dimensionality of the whole-body movement) would produce changes in COP regularity (hypothesis 2). Our results supported the first, but not the second hypothesis: we did find decreased COP regularity immediately after head-shaking, particularly for tilting (ear-to-shoulder) head-shaking, and specifically in the anterior-posterior component of the COP time series. For these trials, we also found decreased regularity in the time series of the first five movement components, as predicted by hypothesis 1 . However, we did not find significant changes in the structure or the dimensionality of the whole-body postural movements, contrary to the prediction of hypothesis 2 . Figure 3 visualizes this finding: if changes in anterior-posterior COP entropy are observed (top graph), then hypothesis 1 predicts changes, particularly in the movement components with substantial anterior-posterior contributions $\left(\mathrm{PM}_{1}, \mathrm{PM}_{3}, \mathrm{PM}_{5}\right.$; middle three graphs), while hypothesis 2 predicts changes in the coordinative complexity (here represented through $\mathrm{rCUM}_{5}$; bottom graph), which were not observed.

The results of the current study disagree with an earlier study of our group, in which we investigated the same research question with a cross-sectional study design [38]. In this earlier study, we found that higher COP-SaEn across participants correlated with both higher entropy of relevant individual movement components and with higher coordinative complexity of the whole-body postural movements. Hence, while the earlier study suggested that the regularity of the control of individual movement components and the coordinative complexity are related, the current findings suggest that moderate perturbations of the sensorimotor control system primarily affect the control of movement components, but do not necessarily perturb their composition or the dimensionality in the resultant overall postural movements. In other words, the control system modifies how individual movement components are controlled (regularity of the temporal structure); it does not necessarily employ additional movement components (coordinative complexity in the sense of movement dimensionality).

The observation that COP entropy was altered predominantly in the anterior-posterior direction is plausible, considering that the medio-lateral direction in normal bipedal stance is well-stabilized between the two legs, whereas in the anterior-posterior movement direction the neuromuscular control plays a more direct role [32,37]. The different control mechanisms in the static position might also play an important role for the observed difference. The anterior-posterior direction is mainly controlled by ankle $\left(\mathrm{PM}_{1}\right)$ and hip $\left(\mathrm{PM}_{3}\right)$ movements, while the medio-lateral direction is controlled mostly by shifting the weight between the legs $\left(\mathrm{PM}_{2}\right)$, reflecting changes in stance [35].

Another observation was that head-shaking in the lateral direction (shoulder-to-ear) seemed to have a more pronounced effect on postural control than head-shaking in a nodding movement. These head-shaking directions may affect the sensory systems differently, particularly the vestibular system. An additional explanation could be that the lateral head movement produces larger strains on internal structures of the brain, particularly on the corpus callosum-a mechanism proposed in recent simulation studies on concussion [50]. 
Tilting head sideways

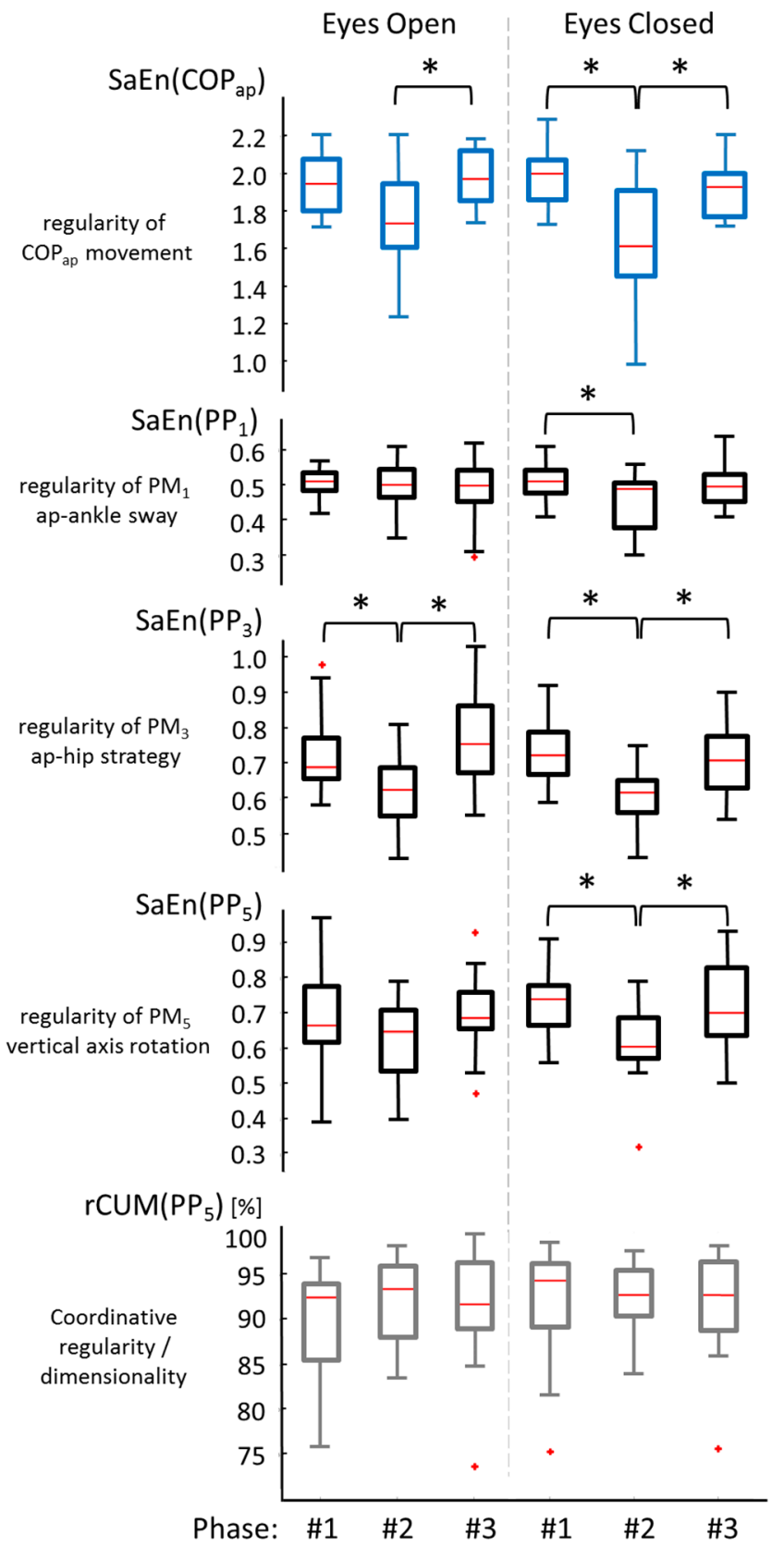

Figure 3. Results of the trials where participants tilted their heads sideways, with a focus on the variables representing the anterior-posterior movement of the body. The boxplots on top show the $\operatorname{SaEn}\left(C O P_{x}\right)$ values as seen in Figure 2. The three graphs below represent the $\operatorname{SaEn}\left(P P_{k}\right)$ values of movement components substantially contributing to anterior-posterior postural movements. Significant differences are indicated $\left(^{*}\right)$. The bottom graph represents coordinative complexity characterized through $r C U M\left(P P_{5}\right)$. No significant effects were observed in this data.

\subsection{Limitations}

The participants were not screened for medication or for chronic lower back pain, which both might have an effect on postural control.

Another important limitation of the current study is the small sample size. On the one hand, we observed statistical significance in a number of variables where it was expected (according to hypothesis 1) - a result which we believe to be reliable. On the other hand, where we did not 
observe significance (e.g., in the tests for hypothesis 2), the small sample size and the often relatively small effect sizes (Tables 4-6) led to a small statistical power. Hypothesis 2 is thus not conclusively disproven. Nevertheless, when comparing effect sizes, and also the graphical representations of variables referencing the two hypotheses, we feel confident to state that the hypothesis 1 mechanism was dominating the changes in COP entropy.

A third limitation is that the head-shaking experiments were relatively modest perturbations of the human postural control system. The findings of the current study can therefore not be generalized to more severe perturbations or to pathological conditions.

Limitations arising from the data analysis approach include that PCA is a linear decomposition method, and that limiting the analysis to the first five PCs represents an approximation of the true postural movements. Also, we limited the entropy calculation to one specific time lag. While multi-scale entropy may provide additional information [51-53], in our experience [37,39], the statistical conclusions were not sensitive to changes in time lag over a large range of physiologically sensible lags.

\section{Conclusions}

The current study found that $C O P_{A P}$ entropy decreased after tilting head movements, indicating a change in the control of posture. The source of these changes in COP entropy were changes in the temporal structure (entropy) of the control of individual movement components, rather than changes in the coordinative complexity (i.e., the dimensionality) of the postural movements.

Supplementary Materials: The following are available online at http://www.mdpi.com/1099-4300/21/6/614/s1, Figure S1: Entropy calculations using different parameters of $\tau, m$, and $r$ were performed and visualized, Video S1: A video sequence of PMs 1-5.

Author Contributions: F.W. and P.F. initially conceived the experiment. P.F. and T.K. designed and conducted the experiment. T.H developed and implemented the analysis procedures; F.W. produced and analyzed the results and wrote the first draft of the paper. F.W. and P.F. contributed equally interpreting the results and to revising and finalizing the manuscript.

Funding: This research was funded by the University of Innsbruck. The corresponding author currently holds a scholarship by the Leopold-Franzens University Innsbruck (funding-code: 2017/2/PSY/SPORT-23).

Acknowledgments: We thankfully acknowledge the contribution of Armin Niederkofler in setting up the measurement equipment. We thank Julia Ossovsky, Christian Stecher, Stefan Fischnaller, Jasmin Suvic, Xheni Dyrmishi, and Maximilian Seidl for their contributions in the collection of the data.

Conflicts of Interest: The authors declare no conflict of interest.

\section{References}

1. Massion, J. Postural control system. Curr. Opin. Neurobiol. 1994, 4, 877-887. [CrossRef]

2. Cavanaugh, J.T.; Guskiewicz, K.M.; Giuliani, C.; Marshall, S.; Mercer, V.; Stergiou, N. Detecting altered postural control after cerebral concussion in athletes with normal postural stability. Br. J. Sports Med. 2005, 39, 805-811. [CrossRef]

3. Memari, A.H.; Ghanouni, P.; Shayestehfar, M.; Ghaheri, B. Postural Control Impairments in Individuals With Autism Spectrum Disorder: A Critical Review of Current Literature. Asian J. Sports Med. 2014, 5. [CrossRef] [PubMed]

4. Tasseel-Ponche, S.; Yelnik, A.P.; Bonan, I.V. Motor strategies of postural control after hemispheric stroke. Neurophysiol. Clin. Neurophysiol. 2015, 45, 327-333. [CrossRef] [PubMed]

5. Manor, B.; Hu, K.; Zhao, P.; Selim, M.; Alsop, D.; Novak, P.; Lipsitz, L.; Novak, V. Altered control of postural sway following cerebral infarction: A cross-sectional analysis. Neurology 2010, 74, 458-464. [CrossRef] [PubMed]

6. Vaugoyeau, M.; Viel, S.; Assaiante, C.; Amblard, B.; Azulay, J.P. Impaired vertical postural control and proprioceptive integration deficits in Parkinson's disease. Neuroscience 2007, 146, 852-863. [CrossRef]

7. Derlich, M.; Kręcisz, K.; Kuczyński, M. Attention demand and postural control in children with hearing deficit. Res. Dev. Disabil. 2011, 32, 1808-1813. [CrossRef] 
8. Rigoldi, C.; Cimolin, V.; Camerota, F.; Celletti, C.; Albertini, G.; Mainardi, L.; Galli, M. Measuring regularity of human postural sway using approximate entropy and sample entropy in patients with Ehlers-Danlos syndrome hypermobility type. Res. Dev. Disabil. 2013, 34, 840-846. [CrossRef]

9. Gruber, A.H.; Busa, M.A.; Gorton III, G.E.; Van Emmerik, R.E.A.; Masso, P.D.; Hamill, J. Time-to-contact and multiscale entropy identify differences in postural control in adolescent idiopathic scoliosis. Gait Posture 2011, 34, 13-18. [CrossRef]

10. Donker, S.F.; Ledebt, A.; Roerdink, M.; Savelsbergh, G.J.P.; Beek, P.J. Children with cerebral palsy exhibit greater and more regular postural sway than typically developing children. Exp. Brain Res. 2008, 184, 363-370. [CrossRef]

11. Galli, M.; Rigoldi, C.; Mainardi, L.; Tenore, N.; Onorati, P.; Albertini, G. Postural control in patients with Down syndrome. Disabil. Rehabil. 2008, 30, 1274-1278. [CrossRef] [PubMed]

12. Gribble, P.A.; Hertel, J. Effect of hip and ankle muscle fatigue on unipedal postural control. J. Electromyogr. Kinesiol. 2004, 14, 641-646. [CrossRef] [PubMed]

13. Gribble, P.A.; Hertel, J. Effect of lower-extremity muscle fatigue on postural control. Arch. Phys. Med. Rehabil. 2004, 85, 589-592. [CrossRef] [PubMed]

14. Melzer, I.; Benjuya, N.; Kaplanski, J. Age-related changes of postural control: Effect of cognitive tasks. Gerontology 2001, 47, 189-194. [CrossRef] [PubMed]

15. Huxhold, O.; Li, S.-C.; Schmiedek, F.; Lindenberger, U. Dual-tasking postural control: Aging and the effects of cognitive demand in conjunction with focus of attention. Brain Res. Bull. 2006, 69, 294-305. [CrossRef] [PubMed]

16. Ramdani, S.; Seigle, B.; Lagarde, J.; Bouchara, F.; Bernard, P.L. On the use of sample entropy to analyze human postural sway data. Med. Eng. Phys. 2009, 31, 1023-1031. [CrossRef] [PubMed]

17. Ella, K.; Kristinsdottir, M.M. Eva Nordell, Gun-Britt Jarnlo, Annika Tjäder, Karl-Göran Thorngren Observation of Vestibular Asymmetry in a Majority of Patients over 50 Years With Fall-Related Wrist Fractures. Acta Otolaryngol. (Stockh.) 2001, 121, 481-485.

18. Guo, L.; Yang, C.; You, Y.; Chen, S.; Yang, C.; Hou, Y.; Wu, W. Underlying mechanisms of Tai-Chi-Chuan training for improving balance ability in the elders. Chin. J. Integr. Med. 2014, 20, 409-415. [CrossRef] [PubMed]

19. Haran, F.J.; Tierney, R.; Wright, W.G.; Keshner, E.; Silter, M. Acute Changes in Postural Control after Soccer Heading. Int. J. Sports Med. 2013, 34, 350-354. [CrossRef] [PubMed]

20. Collins, J.J.; De Luca, C.J. Open-loop and closed-loop control of posture: A random-walk analysis of center-of-pressure trajectories. Exp. Brain Res. 1993, 95, 308-318. [CrossRef] [PubMed]

21. Laughton, C.A.; Slavin, M.; Katdare, K.; Nolan, L.; Bean, J.F.; Kerrigan, D.C.; Phillips, E.; Lipsitz, L.A.; Collins, J.J. Aging, muscle activity, and balance control: Physiologic changes associated with balance impairment. Gait Posture 2003, 18, 101-108. [CrossRef]

22. Donker, S.F.; Roerdink, M.; Greven, A.J.; Beek, P.J. Regularity of center-of-pressure trajectories depends on the amount of attention invested in postural control. Exp. Brain Res. 2007, 181, 1-11. [CrossRef] [PubMed]

23. McCamley, J.D.; Denton, W.; Arnold, A.; Raffalt, P.C.; Yentes, J.M.; McCamley, J.D.; Denton, W.; Arnold, A.; Raffalt, P.C.; Yentes, J.M. On the Calculation of Sample Entropy Using Continuous and Discrete Human Gait Data. Entropy 2018, 20, 764. [CrossRef] [PubMed]

24. Cavanaugh, J.T.; Guskiewicz, K.M.; Giuliani, C.; Marshall, S.; Mercer, V.S.; Stergiou, N. Recovery of Postural Control After Cerebral Concussion: New Insights Using Approximate Entropy. J. Athl. Train. 2006, 41, 305-313. [PubMed]

25. Gao, J.; Hu, J.; Buckley, T.; White, K.; Hass, C. Shannon and Renyi entropies to classify effects of Mild Traumatic Brain Injury on postural sway. PLoS ONE 2011, 6, e24446. [CrossRef] [PubMed]

26. Busa, M.A.; Jones, S.L.; Hamill, J.; van Emmerik, R.E.A. Multiscale entropy identifies differences in complexity in postural control in women with multiple sclerosis. Gait Posture 2016, 45, 7-11. [CrossRef] [PubMed]

27. Wayne, P.M.; Gow, B.J.; Costa, M.D.; Peng, C.-K.; Lipsitz, L.A.; Hausdorff, J.M.; Davis, R.B.; Walsh, J.N.; Lough, M.; Novak, V.; et al. Complexity-Based Measures Inform Effects of Tai Chi Training on Standing Postural Control: Cross-Sectional and Randomized Trial Studies. PLoS ONE 2014, 9, e114731. [CrossRef] [PubMed]

28. Sabatini, A.M. Analysis of postural sway using entropy measures of signal complexity. Med. Biol. Eng. Comput. 2000, 38, 617-624. [CrossRef] 
29. Pincus, S. Approximate entropy (ApEn) as a complexity measure. Chaos Interdiscip. J. Nonlinear Sci. 1995, 5, 110-117. [CrossRef]

30. Rhea, C.K.; Silver, T.A.; Hong, S.L.; Ryu, J.H.; Studenka, B.E.; Hughes, C.M.L.; Haddad, J.M. Noise and Complexity in Human Postural Control: Interpreting the Different Estimations of Entropy. PLOS ONE 2011, 6, e17696. [CrossRef]

31. Winter, D.A.; Prince, F.; Frank, J.S.; Powell, C.; Zabjek, K.F. Unified theory regarding A/P and M/L balance in quiet stance. J. Neurophysiol. 1996, 75, 2334-2343. [CrossRef] [PubMed]

32. Winter, D.A.; Patla, A.E.; Prince, F.; Ishac, M.; Gielo-Perczak, K. Stiffness Control of Balance in Quiet Standing. J. Neurophysiol. 1998, 80, 1211-1221. [CrossRef]

33. Federolf, P.; Roos, L.; Nigg, B.M. Analysis of the multi-segmental postural movement strategies utilized in bipedal, tandem and one-leg stance as quantified by a principal component decomposition of marker coordinates. J. Biomech. 2013, 46, 2626-2633. [CrossRef] [PubMed]

34. Roerdink, M.; Haart, M.D.; Daffertshofer, A.; Donker, S.F.; Geurts, A.C.H.; Beek, P.J. Dynamical structure of center-of-pressure trajectories in patients recovering from stroke. Exp. Brain Res. 2006, 174, 256. [CrossRef] [PubMed]

35. Federolf, P.A. A novel approach to study human posture control: "Principal movements" obtained from a principal component analysis of kinematic marker data. J. Biomech. 2016, 49, 364-370. [CrossRef]

36. Haid, T.H.; Doix, A.-C.M.; Nigg, B.M.; Federolf, P.A. Age Effects in Postural Control Analyzed via a Principal Component Analysis of Kinematic Data and Interpreted in Relation to Predictions of the Optimal Feedback Control Theory. Front. Aging Neurosci. 2018, 10. [CrossRef] [PubMed]

37. Promsri, A.; Haid, T.; Federolf, P. How does lower limb dominance influence postural control movements during single leg stance? Hum. Mov. Sci. 2018, 58, 165-174. [CrossRef] [PubMed]

38. Haid, T.; Federolf, P. Human Postural Control: Assessment of Two Alternative Interpretations of Center of Pressure Sample Entropy through a Principal Component Factorization of Whole-Body Kinematics. Entropy 2018, 20, 30. [CrossRef]

39. Gløersen, Ø.; Federolf, P. Predicting Missing Marker Trajectories in Human Motion Data Using Marker Intercorrelations. PLOS ONE 2016, 11. [CrossRef]

40. Federolf, P.A. A Novel Approach to Solve the "Missing Marker Problem" in Marker-Based Motion Analysis That Exploits the Segment Coordination Patterns in Multi-Limb Motion Data. PLOS ONE 2013, 8, e78689. [CrossRef]

41. Gløersen, Ø.; Myklebust, H.; Hallén, J.; Federolf, P. Technique analysis in elite athletes using principal component analysis. J. Sports Sci. 2018, 36, 229-237. [CrossRef] [PubMed]

42. de Leva, P. Adjustments to Zatsiorsky-Seluyanov's segment inertia parameters. J. Biomech. 1996, 29, 1223-1230. [CrossRef]

43. Daffertshofer, A.; Lamoth, C.J.C.; Meijer, O.G.; Beek, P.J. PCA in studying coordination and variability: A tutorial. Clin. Biomech. 2004, 19, 415-428. [CrossRef] [PubMed]

44. Troje, N.F. Decomposing biological motion: A framework for analysis and synthesis of human gait patterns. J. Vis. 2002, 2, 2-2. [CrossRef] [PubMed]

45. Bockemühl, T.; Troje, N.F.; Dürr, V. Inter-joint coupling and joint angle synergies of human catching movements. Hum. Mov. Sci. 2010, 29, 73-93. [CrossRef] [PubMed]

46. Verrel, J.; Lövdén, M.; Schellenbach, M.; Schaefer, S.; Lindenberger, U. Interacting effects of cognitive load and adult age on the regularity of whole-body motion during treadmill walking. Psychol. Aging 2009, 24, 75-81. [CrossRef] [PubMed]

47. van Emmerik, R.E.A.; van Wegen, E.E.H. On the Functional Aspects of Variability in Postural Control. Exerc. Sport Sci. Rev. 2002, 30, 177. [CrossRef] [PubMed]

48. Estrada, L.; Torres, A.; Sarlabous, L.; Jané, R. Influence of Parameter Selection in Fixed Sample Entropy of Surface Diaphragm Electromyography for Estimating Respiratory Activity. Entropy 2017, 19, 460. [CrossRef]

49. Kanekar, N.; Lee, Y.-J.; Aruin, A.S. Frequency analysis approach to study balance control in individuals with multiple sclerosis. J. Neurosci. Methods 2014, 222, 91-96. [CrossRef]

50. Hernandez, F.; Wu, L.C.; Yip, M.C.; Laksari, K.; Hoffman, A.R.; Lopez, J.R.; Grant, G.A.; Kleiven, S.; Camarillo, D.B. Six Degree-of-Freedom Measurements of Human Mild Traumatic Brain Injury. Ann. Biomed. Eng. 2015, 43, 1918-1934. [CrossRef] 
51. Gow, B.J.; Peng, C.-K.; Wayne, P.M.; Ahn, A.C.; Gow, B.J.; Peng, C.-K.; Wayne, P.M.; Ahn, A.C. Multiscale Entropy Analysis of Center-of-Pressure Dynamics in Human Postural Control: Methodological Considerations. Entropy 2015, 17, 7926-7947. [CrossRef]

52. Reshape scale method: A novel multi scale entropic analysis approach. Phys. Stat. Mech. Its Appl. 2013, 392, 6265-6272. [CrossRef]

53. Federolf, P.; Zandiyeh, P.; Tscharner, V. von Time scale dependence of the center of pressure entropy: What characteristics of the neuromuscular postural control system influence stabilographic entropic half-life? Exp. Brain Res. 2015, 233, 3507-3515. [CrossRef] [PubMed]

(C) 2019 by the authors. Licensee MDPI, Basel, Switzerland. This article is an open access article distributed under the terms and conditions of the Creative Commons Attribution (CC BY) license (http://creativecommons.org/licenses/by/4.0/). 